\title{
Characterization of antibiotic resistance in Listeria spp. isolated from slaughterhouse environments, pork and human infections
}

\author{
Luisa Z. Moreno ${ }^{1,2}$, Renata Paixão ${ }^{2}$, Debora D.S. Gobbi², Daniele C. Raimundo ${ }^{2}$, Thais P. Ferreira ${ }^{2}$, \\ Andrea M. Moreno ${ }^{2}$, Ernesto Hofer ${ }^{3}$, Cristhiane M. F. Reis ${ }^{3}$, Glavur R. Matté ${ }^{1}$, Maria H. Matté ${ }^{1}$ \\ ${ }^{1}$ Laboratório Prática de Saúde Pública, Faculdade de Saúde Pública, Universidade de São Paulo, São Paulo, \\ Brasil \\ ${ }^{2}$ Laboratório de Sanidade Suína e Virologia, Faculdade de Medicina Veterinária e Zootecnia, Universidade de São \\ Paulo, São Paulo, Brasil \\ ${ }^{3}$ Laboratório de Zoonoses Bacterianas, Fundação Instituto Oswaldo Cruz, Rio de Janeiro, Brasil
}

\begin{abstract}
Introduction: Listeria species are susceptible to most antibiotics. However, over the last decade, increasing reports of multidrug-resistant Listeria spp. from various sources have prompted public health concerns. The objective of this study was to characterize the antibiotic susceptibility of Listeria spp. and the genetic mechanisms that confer resistance.

Methodology: Forty-six Listeria spp. isolates were studied, and their minimal inhibitory concentrations of antibiotics were determined by microdilution using Sensititre standard susceptibility MIC plates. The isolates were screened for the presence of $g y r A, p a r C, l d e, l s a(\mathrm{~A})$, $\operatorname{lnu}(\mathrm{A})$, and $m p r F$ by PCR, and the amplified genes were sequenced.

Results: All isolates were susceptible to penicillin, ampicillin, tetracycline, erythromycin, and carbapenems. Resistance to clindamycin, daptomycin, and oxacillin was found among L. monocytogenes and L. innocua, and all species possessed at least intermediate resistance to fluoroquinolones. $G y r A$, parC, and $m p r F$ were detected in all isolates; however, mutations were found only in gyrA sequences. A high daptomycin MIC, as reported previously, was observed, suggesting an intrinsic resistance of Listeria spp. to daptomycin. Conclusions: These results are consistent with reports of emerging resistance in Listeria spp. and emphasize the need for further genotypic characterization of antibiotic resistance in this genus.
\end{abstract}

Key words: Listeria; antibiotic resistance; microdilution; PCR

J Infect Dev Ctries 2014; 8(4):416-423. doi:10.3855/jidc.4188

(Received 02 September 2013 - Accepted 03 December 2013)

Copyright (C) 2014 Moreno et al. This is an open-access article distributed under the Creative Commons Attribution License, which permits unrestricted use, distribution, and reproduction in any medium, provided the original work is properly cited.

\section{Introduction}

The genus Listeria is characterized by Grampositive, facultatively anaerobic rods that are widely distributed in the environment [1]. Eight species are currently described in the Listeria genus: $L$. monocytogenes, $L$. innocua, $L$. seeligeri, $L$. welshimeri, L. ivanovii, L. grayi, L. marthii, and $L$. rocourtiae [2]. Only L. monocytogenes and L. ivanovii are considered to be pathogenic to animals and humans [1]; however, instances of human listeriosis due to L. seeligeri and L. innocua infection have been reported $[3,4]$.

Listeriosis represents a public health concern; its fatality rate can be as high as $30 \%$. The disease primarily affects the elderly, neonates, and immunocompromised individuals, which includes an increasing population of cancer and HIV-positive patients $[1,5,6]$. A positive outcome for listeriosis depends on the early administration of antibiotics. The standard treatment remains the application of high doses of a beta-lactam antibiotic (ampicillin or amoxicillin) alone or in combination with gentamicin; sulfamethoxazole is generally used in the case of betalactam intolerance [7].

Most Listeria species are susceptible to all antibiotics except cephalosporins and fosfomycin, to which they are naturally resistant [8]. However, increasing reports of Listeria strains isolated from various sources that are resistant to penicillin, ampicillin, tetracycline, streptomycin, clindamycin, and even oxacillin and vancomycin represent a major public health concern [9-11]. The genetic mechanisms responsible for these resistances are an important research topic, given that $L$. monocytogenes can acquire resistance genes from, and transfer them to, enterococci, staphylococci, and streptococci $[12,13]$. 
The purpose of this study was to characterize the antibiotic susceptibility profiles of Listeria spp. isolated from slaughterhouse environments and pork and human infections, and the genetic mechanisms that confer resistance.

\section{Methodology}

Bacterial strains

Forty-six Listeria spp. isolates were studied. Of these, 25 were isolated from pork and slaughterhouse environments (15 isolates of $L$. monocytogenes and 10 of $L$. innocua), 11 isolates of $L$. monocytogenes were from human infections, two isolates were L. ivanovii, two isolates were $L$. seeligeri, two isolates were $L$. welshimeri, and four were controls (L. monocytogenes ATCC 19115 and ATCC 19111, and L. innocua ATCC 33090 and CLIP 12612) (Table 1). The environmental and pork isolates had been previously isolated as described by Moreno et al. [14]; the other Listeria spp. isolates were obtained from the Public Health Laboratory (School of Public Health, University of Sao Paulo) collection. Environmental and pork isolates originated from different samples from slaughterhouse environments and carcasses from Sao Paulo state, and human isolates originated from different patients from various Brazilian states (Table 1).

All of the isolates were previously characterized by serotyping according to Seeliger and Höhne's [15] protocol, the catalase test, motility, cultivation in selective agar ALOA (Biolife, Milano, Italy), and $\beta$ hemolysis on sheep blood agar. Species identity was confirmed using 16S rRNA analysis (data not shown). All isolates were stored in stock medium with glycerol at $-80^{\circ} \mathrm{C}$. The isolates were reactivated in brain-heart infusion medium (BHI; BD-Difco, Franklin Lakes, USA) and plated on tryptone soy agar (TSA; Oxoid, Basingstoke, UK) to isolate pure colonies before use.

\section{Antibiotic susceptibility test}

Minimal inhibitory concentrations (MICs) of Listeria isolates were determined by microdilution, as recommended by the Clinical and Laboratory Standards Institute [16], using Sensititre standard susceptibility MIC plates ESB1F and GPALL1F (TREK Diagnostic Systems/Thermo Fisher Scientific, Waltham, USA), which contained over 32 antibiotics at a full range of MICs, including penicillin (0.06-8 $\mu \mathrm{g} / \mathrm{mL})$, oxacillin $(0.25-4 \mu \mathrm{g} / \mathrm{mL})$, ampicillin $(0.12-8$ $\mu \mathrm{g} / \mathrm{mL})$, cefazolin $(8-16 \mu \mathrm{g} / \mathrm{mL})$, cefepime $(1-16$ $\mu \mathrm{g} / \mathrm{mL})$, cefotaxime $(0.25-64 \mu \mathrm{g} / \mathrm{mL})$, ceftazidime (0.25-128 $\mu \mathrm{g} / \mathrm{mL})$, ceftriaxone $(1-128 \mu \mathrm{g} / \mathrm{mL})$, cefoxitin (4-64 $\mu \mathrm{g} / \mathrm{mL}), \quad$ cefpodoxime $\quad(0.25-32$ $\mu \mathrm{g} / \mathrm{mL})$, cephalothin $(8-16 \mu \mathrm{g} / \mathrm{mL})$, imipenem $(0.5-16$ $\mu \mathrm{g} / \mathrm{mL})$, meropenem $(1-8 \mu \mathrm{g} / \mathrm{mL})$, vancomycin $(0.25$ $32 \mu \mathrm{g} / \mathrm{mL})$, daptomycin $(0.5-4 \mu \mathrm{g} / \mathrm{mL})$, gentamycin (2-16 $\mu \mathrm{g} / \mathrm{mL})$, erythromycin $(0.25-4 \mu \mathrm{g} / \mathrm{mL})$, tetracycline $(2-16 \mu \mathrm{g} / \mathrm{mL})$, moxifloxacin $(0.25-4$ $\mu \mathrm{g} / \mathrm{mL})$, levofloxacin $(0.25-4 \mu \mathrm{g} / \mathrm{mL})$, ciprofloxacin (1-2 $\mu \mathrm{g} / \mathrm{mL})$, nitrofurantoin (32-64 $\mu \mathrm{g} / \mathrm{mL})$, clindamycin $(0.5-2 \mu \mathrm{g} / \mathrm{mL})$, chloramphenicol (2-16 $\mu \mathrm{g} / \mathrm{mL})$, rifampicin $(0.5-4 \mu \mathrm{g} / \mathrm{mL})$, linezolid (1-8 $\mu \mathrm{g} / \mathrm{mL}), \quad$ tigecycline $\quad(0.03-0.5 \quad \mu \mathrm{g} / \mathrm{mL})$, quinupristin/dalfopristin $\quad(0.5-4 \quad \mu \mathrm{g} / \mathrm{mL})$, trimethoprim/sulfamethoxazole $(0.5 / 9.5-4 / 76 \mu \mathrm{g} / \mathrm{mL})$, and piperacillin/tazobactam $(4 / 4-64 / 4 \mu \mathrm{g} / \mathrm{mL})$. The GPALL1F plate also included the D-test to assess erythromycin- and clindamycin-inducible resistance. MIC values were manually recorded. S. pneumoniae ATCC 49619 and S. aureus ATCC 29213 were used as quality control strains. The results were interpreted according to $L$. monocytogenes breakpoints for penicillin, ampicillin, and sulfamethoxazole [16], and the staphylococci criteria were used for the other tested antibiotics [17].

\section{PCR detection of antibiotic resistance genes}

Genomic DNA extraction was performed according to Ausubel et al.'s [18] protocol (CTAB).

According to the antibiotic susceptibility results, the isolates were screened for fluoroquinolone resistance. The gyrA and parC genes, which encode subunits of DNA gyrase topoisomerase II and topoisomerase IV, and the lde gene, which encodes an efflux pump associated with fluoroquinolone resistance, were amplified using primer sequences from Godreuil et al. [19] and Romanova et al. [20], respectively. The isolates were also screened for clindamycin resistance. The $l s a(\mathrm{~A})$ and $\ln u(\mathrm{~A})$ genes, which encode enzymes that inactivate clindamycin, were amplified using primer sequences from Singh and Murray [21] and Lina et al. [22], respectively. To amplify the $m p r F$ gene, which is linked to daptomycin resistance, primer sequences were designed based on the homologous gene Lmol695 (mprF forward TGCGGGTGGTCTTTACTTCC; $m p r F$ reverse CGCGAGCAAGTGTGTTGAAA).

PCR reactions and programs were primer specific, followed the recommendations of the respective authors, and were performed using an Eppendorf Mastercycler gradient thermocycler. Each reaction (25 $\mu \mathrm{L}$ ) used $5 \mu \mathrm{L}$ of genomic DNA, MilliQ water, 10X PCR buffer, $1.5 \mathrm{mM} \mathrm{MgCl} 2,200 \mu \mathrm{M}$ of dNTPs (Fermentas Fermentas- Thermo Fisher Scientific Inc., 
Waltham, USA), $200 \mu \mathrm{M}$ of each primer, and $1.25 \mathrm{U}$ of Taq-DNA-polymerase (Promega, Fitchburg, USA). The amplified products were separated by electrophoresis in 1.5\% agarose gels and stained with ethidium bromide $(1 \mu \mathrm{g} / \mathrm{mL})$. Molecular weight determinations were determined using the $1 \mathrm{~Kb}$ Plus DNA Ladder (Fermentas Fermentas- Thermo Fisher Scientific Inc., Waltham, USA).

\section{Sequencing and analysis}

Amplified fragments were purified using the Illustra GFX PCR DNA and Gel Band Purification kit (GE Healthcare Little Chalfont, UK) and sequenced directly by Genomic Engenharia Molecular (Sao Paulo/SP, Brazil). The BIOEDIT Sequence Alignment Editor 7.0.9 [23] was used for sequence analysis. The sequences of the gyrA and parC quinolone resistancedetermining regions (QRDRs) were compared to sequences from isolates with resistant, intermediate, and sensitive fluoroquinolone profiles and to previously published Listeria spp., E. coli, S. aureus, and $S$. pneumoniae QRDR sequence accessions from GenBank (NCBI, Bethesda, USA). For the analysis of $m p r F$, sequences from daptomycin-susceptible and daptomycin-resistant isolates were compared to search for mutations that could explain the resistance phenotype.

\section{Nucleotide sequence accession numbers}

All DNA sequences from this study were deposited in GenBank under accession numbers KC808584 to KC808600.

\section{Results}

The antibiotic resistance of the Listeria species is shown in Table 2. All isolates were susceptible to penicillin, ampicillin, vancomycin, cephalothin, imipenem, and meropenem. Resistance to clindamycin and oxacillin was found among L. monocytogenes and L. innocua isolates and included L. monocytogenes isolates of human origin. It is noteworthy that $37 \%$ of the isolates were resistant to daptomycin, an antibiotic that was recently approved in Latin America and is specific for Gram-positive infections. Furthermore, all studied Listeria species presented at least intermediate resistance to ciprofloxacin, levofloxacin, or moxifloxacin. The antibiotic $\mathrm{MIC}$ ranges, $\mathrm{MIC}_{50}$ and $\mathrm{MIC}_{90}$, are summarized in Table 3. In contrast to resistance profiles observed in Europe and North America, all isolates were susceptible to tetracycline, erythromycin, rifampicin, and trimethoprimsulfamethoxazole. The only difference observed in the resistance frequencies among the human and environmental isolates was that all human isolates presented intermediate resistance to clindamycin (data not shown).

The gyrA and $\operatorname{par} C$ genes were detected in all of the isolates, which was expected because these are constitutive genes encoding subunits of DNA gyrase topoisomerase II and topoisomerase IV, respectively. $M p r F$ was also detected in all of the isolates, whereas $82.6 \%(38 / 46)$ of Listeria isolates were positive for lde. $L s a(\mathrm{~A})$ and $\operatorname{lnu}(\mathrm{A})$ were not detected in any of the isolates. No differences were observed in the phenotypic or genotypic resistance profiles of the Listeria species.

Figure 1. Schematic representation of gyrA QRDR sequences of the Listeria spp. isolates, E. coli, S. aureus, and S. pneumoniae. The codons are numbered according to the L. monocytogenes sequence, and residues that differ among the sequences are highlighted in bold.
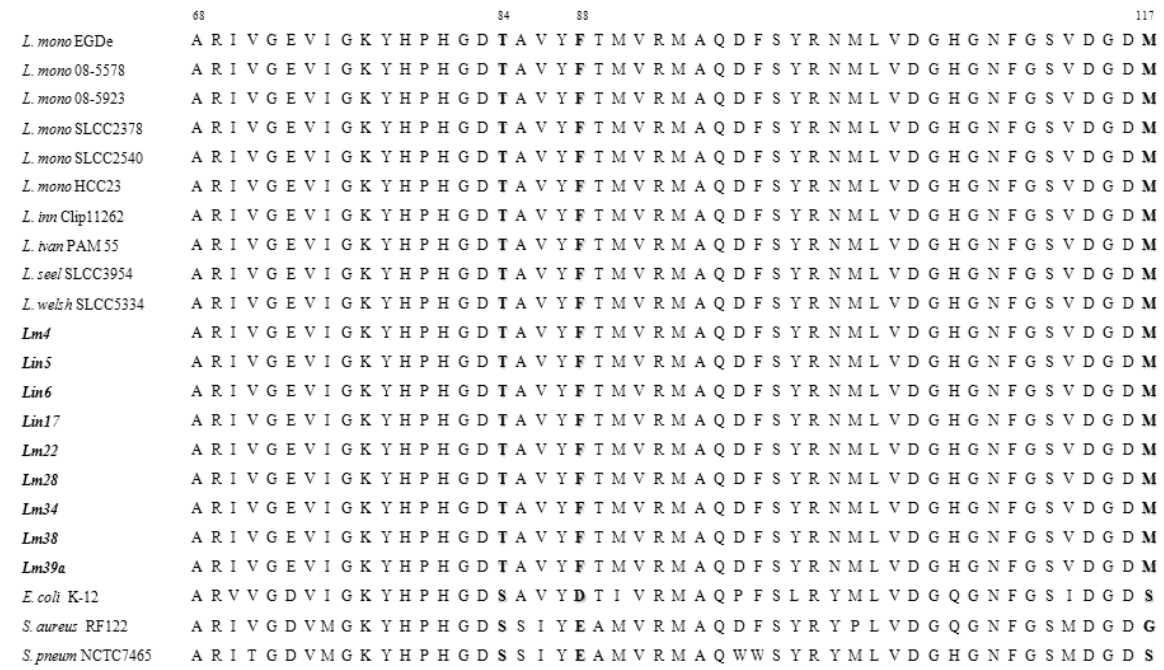

L. mono: L. monocytogenes; L. inn: L. innocua; L. welsh: L. welshimeri; L. seel: $L$. seeligeri; L. ivan: L. ivanovii; S. pneum: S. pneumoniae 
Table 1. Source and phenotypic characteristics of Listeria spp. isolates used in this study

\begin{tabular}{|c|c|c|c|c|c|c|}
\hline Isolate & Species & Serotype & Origin & Site & State & Year \\
\hline$L m 1$ & L. monocytogenes & $1 / 2 \mathrm{a}$ & Slaught 1 & Floor & $\mathrm{SP}$ & 2008 \\
\hline $\operatorname{Lm} 2$ & L. monocytogenes & $1 / 2 b$ & Slaught 1 & Floor & SP & 2008 \\
\hline$L m 3$ & L. monocytogenes & $4 b$ & Market 1 & Floor & SP & 2008 \\
\hline $\operatorname{Lm} 21$ & L. monocytogenes & $1 / 2 \mathrm{a}$ & Slaught 1 & Floor & SP & 2008 \\
\hline $\operatorname{Lm} 22$ & L. monocytogenes & $1 / 2 \mathrm{a}$ & Slaught 1 & Floor & SP & 2008 \\
\hline $\operatorname{Lm} 23$ & L. monocytogenes & $1 / 2 \mathrm{a}$ & Slaught 1 & Floor & SP & 2008 \\
\hline $\operatorname{Lm} 25$ & L. monocytogenes & $1 / 2 \mathrm{a}$ & Slaught 1 & Floor & SP & 2008 \\
\hline $\operatorname{Lm} 26$ & L. monocytogenes & $1 / 2 \mathrm{a}$ & Slaught 1 & Floor & $\mathrm{SP}$ & 2008 \\
\hline $\operatorname{Lm} 27$ & L. monocytogenes & $1 / 2 \mathrm{a}$ & Slaught 1 & Floor & $\mathrm{SP}$ & 2008 \\
\hline $\operatorname{Lm} 28$ & L. monocytogenes & $1 / 2 \mathrm{a}$ & Market 2 & Pork & $\mathrm{SP}$ & 2008 \\
\hline $\operatorname{Lm} 29$ & L. monocytogenes & $1 / 2 \mathrm{a}$ & Market 2 & Pork & SP & 2008 \\
\hline $\operatorname{Lm} 30$ & L. monocytogenes & $1 / 2 \mathrm{a}$ & Market 2 & Pork & SP & 2008 \\
\hline $\operatorname{Lm} 31$ & L. monocytogenes & $1 / 2 \mathrm{a}$ & Market 2 & Pork & SP & 2008 \\
\hline Lm4 & L. monocytogenes & $1 / 2 \mathrm{a}$ & Market 2 & Pork & SP & 2008 \\
\hline $\operatorname{Lm} 33$ & L. monocytogenes & $1 / 2 \mathrm{a}$ & Market 2 & Pork & SP & 2008 \\
\hline $\operatorname{Lm} 34$ & L. monocytogenes & $1 / 2 \mathrm{a}$ & Human & Blood & DF & 1989 \\
\hline $\operatorname{Lm} 35$ & L. monocytogenes & $4 \mathrm{~b}$ & Human & Blood & RJ & 2004 \\
\hline $\operatorname{Lm} 36$ & L. monocytogenes & $4 b$ & Human & Blood & SP & 1997 \\
\hline $\operatorname{Lm} 37$ & L. monocytogenes & $4 b$ & Human & $\mathrm{CSF}$ & SP & 1982 \\
\hline $\operatorname{Lm} 38$ & L. monocytogenes & $1 / 2 b$ & Human & $\mathrm{CSF}$ & PR & 1983 \\
\hline $\operatorname{Lm} 39$ & L. monocytogenes & $1 / 2 \mathrm{a}$ & Human & Placenta & PE & 1978 \\
\hline $\operatorname{Lm} 39 a$ & L. monocytogenes & $1 / 2 \mathrm{a}$ & Human & Placenta & PE & 1978 \\
\hline $\operatorname{Lm} 40$ & L. monocytogenes & $1 / 2 \mathrm{a}$ & Human & Blood & SP & 1985 \\
\hline $\operatorname{Lm} 41$ & L. monocytogenes & $4 \mathrm{~b}$ & Human & $\mathrm{CSF}$ & SP & 1997 \\
\hline $\operatorname{Lm} 42$ & L. monocytogenes & $4 b$ & Human & $\mathrm{CSF}$ & SP & 1997 \\
\hline $\operatorname{Lm} 43$ & L. monocytogenes & $1 / 2 \mathrm{a}$ & Human & $\mathrm{CSF}$ & PR & 1983 \\
\hline $\operatorname{Lin} 5$ & L. innocua & $6 a$ & Market 1 & Floor & SP & 2008 \\
\hline $\operatorname{Lin} 6$ & L. innocua & $6 a$ & Slaught 2 & Floor & SP & 2008 \\
\hline $\operatorname{Lin} 7$ & L. innocua & $6 a$ & Slaught 2 & Floor & SP & 2008 \\
\hline $\operatorname{Lin} 8$ & L. innocua & $6 a$ & Slaught 2 & Floor & SP & 2008 \\
\hline $\operatorname{Lin} 9$ & L. innocua & $6 a$ & Slaught 2 & Floor & SP & 2008 \\
\hline $\operatorname{Lin} 16$ & L. innocua & $6 a$ & Slaught 1 & Floor & SP & 2006 \\
\hline $\operatorname{Lin} 17$ & L. innocua & $6 a$ & Slaught 1 & Floor & SP & 2006 \\
\hline $\operatorname{Lin} 18$ & L. innocua & $6 a$ & Slaught 1 & Floor & SP & 2006 \\
\hline $\operatorname{Lin} 19$ & L. innocua & $6 a$ & Slaught 1 & Floor & SP & 2006 \\
\hline $\operatorname{Lin} 20$ & L. innocua & $6 a$ & Slaught 1 & Floor & SP & 2006 \\
\hline Lwe12 & L. welshimeri & - & CIP 8149 & - & - & - \\
\hline Lwe49 & L. welshimeri & - & - & - & - & - \\
\hline Lsel3 & L. seeligeri & - & CIP 100100 & - & - & - \\
\hline Lse14 & L. seeligeri & - & - & - & - & - \\
\hline Liv47 & L. ivanovii & - & ATCC 19119 & - & - & - \\
\hline $\operatorname{Liv} 48$ & L. ivanovii & - & - & - & - & - \\
\hline $\operatorname{Lm} 10$ & L. monocytogenes & $4 b$ & ATCC 19115 & - & - & - \\
\hline $\operatorname{Lm} 15$ & L. monocytogenes & $1 / 2 \mathrm{a}$ & ATCC 19111 & - & - & - \\
\hline $\operatorname{Lin} 11$ & L. innocua & $6 a$ & ATCC 33090 & - & - & - \\
\hline $\operatorname{Lin} 46$ & L. innocua & $6 a$ & CLIP 12612 & - & - & - \\
\hline
\end{tabular}

Lm: L. monocytogenes; Lin: L. innocua; Liv: L. ivanovii; Lwe: L. welshimeri; Lse: L. seeligeri; Slaught1: Slaughterhouse 1; Slaught2: Slaughterhouse 2; CSF: cerebrospinal fluid; SP: Sao Paulo; RJ: Rio de Janeiro; DF: Distrito Federal; PE: Pernambuco; PR: Paraná 
Table 2. Resistance profiles and MIC values of Listeria species by antibiotic - N (\%)

\begin{tabular}{|c|c|c|c|c|c|c|c|c|c|c|c|c|c|}
\hline \multirow{2}{*}{ Antibiotic } & \multicolumn{3}{|c|}{ MIC $(\mu \mathrm{g} / \mathrm{mL})$} & \multicolumn{2}{|c|}{ L. monocytogenes } & \multicolumn{2}{|c|}{ L. innocua } & \multicolumn{2}{|c|}{ L. welshimeri } & \multicolumn{2}{|c|}{ L. seeeligeri } & \multicolumn{2}{|c|}{ L. ivanovii } \\
\hline & Range & $50 \%$ & $90 \%$ & I & $\mathbf{R}$ & I & $\mathbf{R}$ & I & $\mathbf{R}$ & I & $\mathbf{R}$ & I & $\mathbf{R}$ \\
\hline Penicillin & $0.06-1$ & 0.25 & 0.5 & 0 & 0 & 0 & 0 & 0 & 0 & 0 & 0 & 0 & 0 \\
\hline Oxacillin & $0.5-8$ & 2 & 4 & 0 & $5(17.9)$ & 0 & $6(50.0)$ & 0 & 0 & 0 & $1(50.0)$ & 0 & 0 \\
\hline Ampicillin & $0.12-1$ & 0.12 & 0.5 & 0 & 0 & 0 & 0 & 0 & 0 & 0 & 0 & 0 & 0 \\
\hline Cefazolin & 8 & 8 & 8 & 0 & 0 & 0 & 0 & 0 & 0 & 0 & 0 & 0 & 0 \\
\hline Cefepime & $1-32$ & 16 & 32 & $3(10.7)$ & $8(28.6)$ & $3(25.0)$ & $8(64.3)$ & 0 & $1(50.0)$ & $1(50.0)$ & 0 & 0 & 0 \\
\hline Cefotaxime & $0.25-128$ & 8 & 64 & $3(10.7)$ & $6(23.1)$ & $3(25.0)$ & $6(50.0)$ & $1(50.0)$ & 0 & $\begin{array}{c}2 \\
(100.0)\end{array}$ & 0 & 0 & 0 \\
\hline Ceftazidime & $4-256$ & 256 & 256 & 0 & $\begin{array}{c}28 \\
(100.0)\end{array}$ & 0 & $\begin{array}{c}12 \\
(100.0)\end{array}$ & 0 & $\begin{array}{c}2 \\
(100.0)\end{array}$ & 0 & $\begin{array}{c}2 \\
(100.0)\end{array}$ & 0 & $1(50.0)$ \\
\hline Ceftriaxone & $1-256$ & 16 & 128 & $8(28.6)$ & $7(25.0)$ & $5(41.7)$ & $7(58.3)$ & $1(50.0)$ & 0 & $\begin{array}{c}2 \\
(100.0)\end{array}$ & 0 & $1(50.0)$ & 0 \\
\hline Cephalothin & 8 & 8 & 8 & 0 & 0 & 0 & 0 & 0 & 0 & 0 & 0 & 0 & 0 \\
\hline Imipenem & 0.5 & 0.5 & 0.5 & 0 & 0 & 0 & 0 & 0 & 0 & 0 & 0 & 0 & 0 \\
\hline Meropenem & 1 & 1 & 1 & 0 & 0 & 0 & 0 & 0 & 0 & 0 & 0 & 0 & 0 \\
\hline Vancomycin & $0.5-1$ & 1 & 1 & $1(3.6)$ & 0 & 0 & 0 & 0 & 0 & 0 & 0 & 0 & 0 \\
\hline Daptomycin & $0.5-8$ & 1 & 4 & 0 & $4(14.3)$ & - & $10(83.3)$ & - & $\begin{array}{c}2 \\
(100.0)\end{array}$ & - & $1(50.0)$ & - & 0 \\
\hline Gentamycin & $2-4$ & 2 & 2 & 0 & 0 & 0 & 0 & 0 & 0 & 0 & 0 & 0 & 0 \\
\hline Erythromycin & $0.25-0.5$ & 0.25 & 0.25 & 0 & 0 & 0 & 0 & 0 & 0 & 0 & 0 & 0 & 0 \\
\hline Tetracycline & 2 & 2 & 2 & 0 & 0 & 0 & 0 & 0 & 0 & 0 & 0 & 0 & 0 \\
\hline Moxifloxacin & $0.5-2$ & 1 & 1 & $13(46.4)$ & $1(3.6)$ & $8(64.3)$ & 0 & 0 & 0 & $\begin{array}{c}2 \\
(100.0)\end{array}$ & 0 & $1(50.0)$ & 0 \\
\hline Levofloxacin & $1-4$ & 2 & 2 & $20(71.4)$ & 0 & $10(83.3)$ & 0 & $1(50.0)$ & 0 & $1(50.0)$ & $1(50.0)$ & $2(100.0)$ & 0 \\
\hline Ciprofloxacin & $1-4$ & 2 & 4 & $19(67.9)$ & $2(7.1)$ & $10(83.3)$ & $1(8.3)$ & $1(50.0)$ & 0 & 0 & $\begin{array}{c}2 \\
(100.0)\end{array}$ & $1(50.0)$ & 0 \\
\hline Nitrofurantoin & $32-128$ & 64 & 128 & $9(32.1)$ & $16(57.1)$ & $6(50.0)$ & $5(41.7)$ & $\begin{array}{c}2 \\
(100.0)\end{array}$ & 0 & $1(50.0)$ & $1(50.0)$ & $2(100.0)$ & 0 \\
\hline Clindamycin & $0.5-4$ & 2 & 4 & $24(85.7)$ & $3(10.7)$ & $6(50.0)$ & $6(50.0)$ & $\begin{array}{c}2 \\
(100.0)\end{array}$ & 0 & $\begin{array}{c}2 \\
(100.0)\end{array}$ & 0 & $1(50.0)$ & 0 \\
\hline Chloramphenicol & $2-16$ & 8 & 16 & $2(7.1)$ & 0 & $4(33.3)$ & 0 & 0 & 0 & $1(50.0)$ & 0 & 0 & 0 \\
\hline Rifampicin & 0.5 & 0.5 & 0.5 & 0 & 0 & 0 & 0 & 0 & 0 & 0 & 0 & 0 & 0 \\
\hline Quinuptn/Dalfoptn & $0.5-2$ & 1 & 1 & 0 & 0 & $1(8.3)$ & 0 & 0 & 0 & 0 & 0 & 0 & 0 \\
\hline Linezolid & $1-4$ & 2 & 4 & - & 0 & - & 0 & - & 0 & - & 0 & - & 0 \\
\hline Trimetop/Sulfametx & $0.5 / 9.5$ & $0.5 / 9.5$ & $0.5 / 9.5$ & - & 0 & - & 0 & - & 0 & - & 0 & - & 0 \\
\hline Pipe/Tazo & $4 / 4$ & $4 / 4$ & $4 / 4$ & - & 0 & - & 0 & - & 0 & - & 0 & - & 0 \\
\hline Tigecycline & $0.03-0.12$ & 0.06 & 0.06 & - & 0 & - & 0 & - & 0 & - & 0 & - & 0 \\
\hline
\end{tabular}

I: intermediate; R: resistant; Quinuptn/Dalfoptn: Quinupristin/Dalfopristin; Trimetop/Sulfametx: Trimethoprim/Sulfamethoxazole; Pipe/Tazo: Piperacillin/Tazobactam 
The QRDR sequences of gyrA and parC from Listeria isolates with resistant, intermediate, and sensitive fluoroquinolone profiles were analyzed and compared to previously published sequences to search for mutations that could explain these resistance profiles. All of the Listeria gyrA QRDR sequences, including those that were previously published, contained the mutations Thr84Ser, Phe88Asp / Phe88Glu and Met117Ser / Met117Gly when compared to E. coli, S. aureus, and S. pneumoniae sequences (Figure 1). No differences were identified in the parC or $m p r F$ sequences from daptomycinsusceptible and daptomycin-resistant isolates.

\section{Discussion}

The results of this study suggest the presence of a high level of resistance to clindamycin, daptomycin, and fluoroquinolone in Listeria spp. Although natural resistance to third- and fourth-generation cephalosporins was observed, the tested Listeria isolates were susceptible to the antibiotics that are currently used to treat listeriosis (i.e., penicillin, ampicillin, gentamycin, and trimethoprimsulfamethoxazole); consequently, these isolates do not represent any risk when these traditional treatments are used. However, certain L. monocytogenes, $L$. innocua, L. seeligeri, and L. welshimeri isolates were resistant to oxacillin, clindamycin, and daptomycin, which are antibiotics that are widely used in hospitals to treat Gram-positive infections [10]. This study confirms the emergence of Listeria spp. from different origins that are resistant to one or more antibiotics.

Resistance to erythromycin, rifampicin, trimethoprim-sulfamethoxazole and, particularly, tetracycline, was not observed in the studied isolates. This resistance profile is relatively common in Europe and North America [11,24,25] and is consistent with the identification of the tet, aad, and erm resistance genes in Listeria spp. [13]. In Brazil, this resistance profile has not been commonly observed, and Listeria isolates are susceptible to most antibiotics [26-28]. For this reason, the study of antibiotic resistance in Listeria has not progressed to the point that the molecular mechanisms of resistance should receive significant attention. However, the emergence of clindamycin, oxacillin, and fluoroquinolone resistance is noteworthy $[28,29]$ and demands attention due to the risk of increasing multidrug resistance in Listeria and the possibility of its transference to other bacteria.

The only resistance genes that were detected in this study were related to fluoroquinolone and daptomycin resistance. Fluoroquinolone resistance in
Gram-positive bacteria is usually related to mutations in the gyrA and parC genes, especially in the QRDRs, because these genes encode subunits of DNA gyrase topoisomerase II and topoisomerase IV, which are targets of fluoroquinolones. The resistance can also result from the action of efflux pumps that actively export the antibiotic, such as lde. In the present study, the gyrA sequences presented mutations that were previously described by Lampidis et al. [30], who only differentiated the gyrA QRDR of Listeria from those of other bacteria. Because these mutations are present in all Listeria sequences of both susceptible and resistant isolates, it is not possible to confirm their role in the development of resistance; however, they represent residues that are commonly associated with fluoroquinolone resistance [31]. No differences were identified in the $\operatorname{parC}$ sequences; however, little information is available regarding parC mutations in Listeria that are related to quinolone resistance.

The lde sequences also presented no differences. Despite the fact that the lde efflux pump is associated with fluoroquinolone resistance in Gram-positive bacteria, lde appears to be ubiquitous in $L$. monocytogenes and, therefore, its detection is not sufficient to confirm its role in the development of resistance. Further studies that use efflux pump inhibitors, such as reserpine, should be developed to determine the origin of fluoroquinolone resistance in these isolates. Additionally, the possibility that lde hyperexpression could lead to fluoroquinolone resistance [20] should be studied to enhance our knowledge of the possible mechanisms of quinolone resistance in Listeria.

The gene $\operatorname{mprF}$ was detected in isolates that were susceptible and resistant to daptomycin, and no differences were identified in the resulting sequences. Daptomycin resistance has already been described in Staphylococcus spp. and Enterococcus spp. to involve four genes (including $m p r F$ ) that have homologs in $L$. monocytogenes [32]. Although few studies have tested Listeria for susceptibility to daptomycin, a high daptomycin MIC (4 mg/L) has been reported in clinical isolates of L. monocytogenes. Nonetheless, the mechanism of this resistance has not been elucidated [33]. These results could indicate an intrinsic resistance of Listeria spp. to daptomycin.

Because the mechanism of clindamycin activity is similar to that of erythromycin and chloramphenicol, cross-resistance of these compounds has unsurprisingly been observed [34]. However, the present study reports only clindamycin resistance and found negative results for erythromycin- and 
clindamycin-inducible resistance. These results corroborate the theory of a specific enzyme that inactivates clindamycin, as previously described for Staphylococcus spp. The genes $l s a(\mathrm{~A})$ and $\ln u(\mathrm{~A})$ appear to be related to this type clindamycin resistance in Enterococcus spp. and Staphylococcus spp. [21,22]. Although $l s a(\mathrm{~A})$ and $\ln u(\mathrm{~A})$ were not detected, the clindamycin resistance that was reported in this study appears to be related to enzyme inactivation because cross-resistance was not observed with erythromycin and chloramphenicol, and, therefore, other lsa and lnu genes should be screened to prove this theory.

These results are consistent with reports of emergence of resistance in Listeria spp. and emphasize the need for further studies of the genotypic characterization of antibiotic resistance in Listeria to determine their resistance mechanisms and their potential as reservoirs of transferable resistance genes. It is also necessary to develop breakpoints for other antibiotics in addition to those currently used for listeriosis treatment to enhance the interpretation of antibiogram results. Based on the results of this study, we suggest the possibility of intrinsic daptomycin resistance in Listeria spp. This resistance should be further studied because of the use of this antibiotic in hospital treatments and the implications of its resistance mechanisms for other Gram-positive bacteria.

\section{Acknowledgements}

This study was sponsored by FAPESP (process 2010/19005-4) and CAPES - Coordenação de Aperfeiçoamento de Pessoal de Nível Superior.

\section{References}

1. Farber JM, Peterkin PI (1991) Listeria monocytogenes, a food-borne pathogen. Microbiol Rev 55: 476-511.

2. Graves LM, Helsel LO, Steigerwalt AG, Morey RE, Daneshvar MI, Roof SE, Orsi RH, Fortes ED, Milillo SR, den Bakker HC, Wiedmann M, Swaminathan B, Sauders BD (2010) Listeria marthii sp. nov., isolated from the natural environment, Finger Lakes National Forest. Int J Syst Evol Microbiol 60: 1280-1288.

3. Perrin M, Bemer M, Delamare C (2003) Fatal case of Listeria innocua bacteremia. J Clin Microbiol 41: 5308-5309.

4. Rocourt J, Hof H, Schrettenbrunner A, Malinverni R, Bille J (1986) Acute purulent Listeria seeligeri meningitis in an immunocompetent adult. Schweiz Med Wochenschr 116: 248-251.

5. Goulet V, Hebert M, Hedberg C, Laurent E, Vaillant V, De Valk H, Desenclos JC (2011) Incidence of listeriosis and related mortality among groups at risk of acquiring listeriosis. Clin Infect Dis 54: 652-660.

6. Safdar A, Armstrong D (2003) Listeriosis in patients at a comprehensive cancer center, 1955-1997. Clin Infect Dis 37: 359-364.
7. Hof H (2004) An update on the medical management of listeriosis. Expert Opin Pharmacother 5: 1727-1735.

8. Troxler R, Von Graevenitz A, Funke G, Wiedemann A, Stock I (2000) Natural antibiotic susceptibility of Listeria species: $L$. grayi, L. innocua, $L$. ivanovii, $L$. monocytogenes, $L$. seeligeri and L. welshimeri strains. Clin Microbiol Infect 6: 525-535.

9. Chen YB, Pyla R, Kim TJ, Silva JL, Jung YS (2010) Antibiotic resistance in Listeria species isolated from catfish fillets and processing environment. Letters Appl Microbiol 50: 626-632.

10. Conter M, Paludi D, Zanardi E, Ghidini S, Vergara A, Ianieri A (2009) Characterization of antimicrobial resistance of foodborne Listeria monocytogenes. Int J Food Microbiol 128: 497-500.

11. Walsh D, Duffy G, Sheridan JJ, Blair IS, McDowell DA (2001) Antibiotic resistance among Listeria, including Listeria monocytogenes, in retail foods. J Appl Microbiol 90: 517-522.

12. Charpentier E, Courvalin P (1999) Antibiotic resistance in Listeria spp. Antimicrob Agents Chemother 43: 2103-2108.

13. Lungu B, O'Bryan CA, Muthaiyan A, Milillo SR, Johnson MG, Crandall PG, Ricke SC (2011) Listeria monocytogenes: Antibiotic Resistance in Food Production. Foodborne Pathog Dis 8: $569-578$.

14. Moreno LZ, Paixão R, Gobbi DD, Raimundo DC, Ferreira TP, Hofer E, Matte MH, Moreno AM (2012) Characterization of atypical Listeria innocua isolated from swine slaughterhouses and meat markets. Res Microbiol 163: 268271.

15. Seeliger HPR and Höhne K (1979) Serotyping of Listeria monocytogenes and related species. Meth Microbiol 13: 3149.

16. Clinical and Laboratory Standards Institute (CLSI) (2006) Methods for antimicrobial dilution and disk susceptibility testing of infrequently isolated or fastidious bacteria. Approved guideline M45-A. Wayne, PA: CLSI.

17. Clinical and Laboratory Standards Institute (CLSI) (2011) Performance Standards for Antimicrobial Susceptibility Testing; Twenty-first Informational Supplement (M100-S21). Wayne, PA: CLSI.

18. Ausubel FM, Brent R, Kingston RE, Moore DD, Seidman JG, Smith JA, Struhl K (1995) Short Protocols in Molecular Biology. New York: John Wiley \& Sons 1104 p.

19. Godreuil S, Galimand M, Gerbaud G, Jacquet C, Courvalin P (2003) Efflux pump Lde is associated with fluoroquinolone resistance in Listeria monocytogenes. Antimicrob Agents Chemother 47: 704-708.

20. Romanova NA, Wolffs PF, Brovko LY, Griffiths MW (2006) Role of efflux pumps in adaptation and resistance of Listeria monocytogenes to benzalkonium chloride. Appl Environ Microbiol 72: 3498-3503.

21. Singh KV, Murray BE (2005) Differences in the Enterococcus faecalis lsa locus that influence susceptibility to quinupristin-dalfopristin and clindamycin. Antimicrob Agents Chemother 49: 32-39.

22. Lina G, Quaglia A, Reverdy ME, Leclercq R, Vandenesch F, Etienne J (1999) Distribution of genes encoding resistance to macrolides, lincosamides, and streptogramins among staphylococci. Antimicrob Agents Chemother 43: 1062-1066.

23. Hall TA (1999) BioEdit: a user-friendly biological sequence alignment editor and analysis program for Windows 95/98/NT. Nucleic Acids Sym Series 41: 95-98. 
24. Granier SA, Moubareck, Colaneri C, Lemire A, Roussel S, Dao TT, Courvalin P, Brisabois A (2011) Antimicrobial resistance of Listeria monocytogenes isolates from food and the environment in France over a 10-year period. Appl Environ Microbiol 77: 2788-2790.

25. Srinivasan V, Nam HM, Nguyen LT, Tamilselvam B, Murinda SE, Oliver SP (2005) Prevalence of antimicrobial resistance genes in Listeria monocytogenes isolated from dairy farms. Foodborne Dis 2: 201-211.

26. De Nes F, Riboldi GP, Frazzon APG, d'Azevedo PA, Frazzon J (2010) Antimicrobial resistance and investigation of the molecular epidemiology of Listeria monocytogenes in dairy products. Rev Socied Bras Med Tropical 43: 382-385.

27. Hofer E, Oliveira LMA (1988) Sensibilidade antimicrobiana em amostras de Listeria isoladas de diferentes fontes e regiões do Brasil. Rev Microbiol 19: 109-112.

28. Reis CMF, Barbosa AV, Rusak LA, Vallim DC, Hofer E (2011) Antimicrobial susceptibilities of Listeria monocytogenes human strains isolated from 1970 to 2008 in Brazil. Rev Socied Bras Med Tropical 44: 173-176.

29. Mantilla SPS, Franco RM, Oliveira LAT, De Oliveira, Santos EB, Gouvêa R (2008) Resistência antimicrobiana de bactérias do gênero Listeria spp. isoladas de carne moída bovina. Braz J Vet Res Anim Sci 45: 116-121.

30. Lampidis R, Kostrewa D, Hof H (2002) Molecular characterization of the genes encoding DNA gyrase and topoisomerase IV of Listeria monocytogenes. J Antimicrob Chemother 49: 917-924.

31. Piddock LJ (1999) Mechanisms of fluoroquinolone resistance: an update 1994-1998. Drugs 58: 11-18.

32. Palmer KL, Daniel A, Hardy C, Silverman J, Gilmore MS (2011) Genetic Basis for Daptomycin Resistance in Enterococci. Antimicrob Agents Chemother 55: 3345-3356.

33. Spanjaard L, Vandenbroucke-Grauls CMJE (2008) Activity of Daptomycin against Listeria monocytogenes isolates from Cerebrospinal Fluid. Antimicrob Agents Chemother 52: 18501851.

34. Depardieu F, Podglajen I, Leclercq R, Collatz E, Courvalin P (2007) Modes and modulations of antibiotic resistance gene expression. Clin Microbiol Rev 20: 79-114.

\section{Corresponding author}

Luisa Zanolli Moreno

Laboratório Prática de Saúde Pública

Faculdade de Saúde Pública, Universidade de São Paulo

Av. Dr. Arnaldo, 715 - CEP: 01246 904, São Paulo, Brasil

Phone: + $55113061-7753$

Email: luzanolli@gmail.com

Conflict of interests: No conflict of interests is declared. 